\title{
Magnetic Properties of $\alpha-\mathrm{Fe}-\mathrm{Nd}(\mathrm{Fe}, \mathrm{TM})_{12} \mathrm{~N}_{\mathbf{x}}$ Exchange Spring Magnets Synthesized by Mechanical Alloying
}

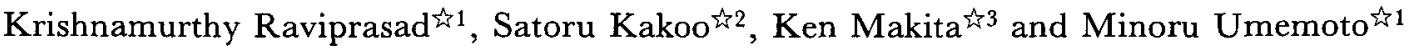 \\ it Faculty of Engineering, Department of Production Systems Engineering, Toyohashi University of Technology, \\ Tenpaku-cho, Toyohashi 441. 22 Graduate School, Department of Production Systems Engineering, Toyohashi \\ University of Technology, Tenpaku-cho, Toyohashi 441. $\sharp_{3}^{3}$ Sumitomo Special Metals Co. Ltd., 2-15-17 Egawa \\ Shimamoto-cho Mishima-gun, Osaka 618.
}

Received July 28, 1995

\section{SYNOPSIS}

The usefulness of a permanent magnet depends on its energy product $(\mathrm{BH})_{\max }$ and it is desirable to increase both the coercivity and remanence. Mechanical alloying with its inherent advantage of grain refinement is expected to result in enhanced coercivity. The advantage of grain size refinement by mechanical alloying is fully utilized, if this can lead to remanence enhancement at the same time. Such a thing is possible if nano scale mixture of exchange coupled hard and soft phases are produced. A magnet with such a two phase mixture is called exchange spring magnet. In the present study exchange spring magnets of $\alpha-\mathrm{Fe}-\mathrm{Nd}(\mathrm{Fe}, \mathrm{TM})_{12} \mathrm{~N}_{\mathrm{x}}$ ( where $\mathrm{TM}=\mathrm{V}$, Mo ) are synthesized by mechanical alloying and a two stage heat treatment. The effect of nitrogenation condition on the magnetic properties has been studied. The optimum nitrogenation temperature was found to be $673 \mathrm{~K}$. Exchange spring magnet of $\alpha-\mathrm{Fe}-\mathrm{Nd}(\mathrm{Fe}, \mathrm{Mo})_{12} \mathrm{~N}_{\mathrm{x}}$ showed a maximum energy product of $48 \mathrm{~kJ} / \mathrm{m}^{3}$ and a spring back of $50 \%$.

\section{KEY WORDS}

mechanical alloying, exchange spring magnet, coercivity, remanence.

\section{Introduction}

The suitability of the mechanical alloying technique for the synthesis of permanent magnets has been demonstrated by the pioneering work of Schultz and co-workers ${ }^{1-5)}$. As the usefulness of a permanent magnet depends on its energy product $(\mathrm{BH})_{\max }$, it is desirable to increase both the coercivity and remanence. Mechanical alloying with its inherent advantage of grain refinement is expected to result in enhanced coercivity. At the same time, efforts to enhance the remanence of these isotropic permanent magnets led to the development of exchange spring magnets ${ }^{6-}$ 10). Exchange spring magnets are a new class of permanent magnets with exchange coupled hard and soft phases. The hysteresis loop is characteristic of a single phase material, even though magnetically two distinct phases are present. The soft phase contributes to the enhanced remanence and the hard phase to the coercivity. As $\alpha-\mathrm{Fe}$ has the highest magnetic moment per atom, it is logical that one tries to synthesize exchange spring mag-nets with $\alpha-\mathrm{Fe}$ as the soft phase and a good hard magnetic phase. Rare earth transition metal compounds with 2:17 structure $\left(\mathrm{Th}_{2} \mathrm{Zn}_{17}\right.$ type or $\mathrm{Th}_{2} \mathrm{Ni}_{17}$ type) or 1:12 structure (ThMn $\mathrm{T}_{12}$ type) are found to exhibit good hard magnetic properties ${ }^{11-14)}$. The limitations imposed by the low Curie temperature (Tc) could be overcome by introducing interstitial nitrogen or carbon ${ }^{15-18)}$. It is interesting to mention here that the interstitially nitrided or carburized 2:17 phase with $\mathrm{Sm}$ shows uniaxial anisotropy, whereas, interstially nitrided or carburized $1: 12$ with $\mathrm{Nd}$ shows uniaxial anisotropy. As $\mathrm{Nd}$ is cheaper than $\mathrm{Sm}$ it is desirable to produce exchange spring magnets with $\mathrm{Nd}$ rather than Sm. A comparison between the 1:12 and 2:17 phases is shown in Table 1. Though a number of studies has been carried out on the exchange spring 
magnets with $2: 17$ as the hard phase $e^{9,10,19)}$, the possibility of exchange spring magnets with $1: 12$ as the hard phase has been overlooked. In the present article we report the results on the synthesis and magnetic properties of the hitherto unexplored exchange spring magnets of $\alpha-\mathrm{Fe}-\mathrm{Nd}(\mathrm{Fe}, \mathrm{TM})_{12} \mathrm{~N}_{\mathrm{x}}$, where $\mathrm{TM}=\mathrm{V}$ and Mo.

Table 1 : Comparison of 1:12 and 2:17 hard phases

\section{Advantages of $1: 12$ over $2: 17$}

1. Nd is cheaper than $\mathrm{Sm}$

2. Theoretical estimation of maximum energy product

$$
\begin{array}{ll}
2: 17 & 3975 \mathrm{~kJ} / \mathrm{m}^{3} \\
1: 12 & 4373 \mathrm{~kJ} / \mathrm{m}^{3}
\end{array}
$$

3. Easy magnetization direction at room temperature

$\mathrm{Sm}_{2} \mathrm{Fe}_{17}$ ab plane $\mathrm{Nd}(\mathrm{Fe}, \mathrm{TM})_{12} \quad \mathrm{C}$-axis $\mathrm{Sm}_{2} \mathrm{Fe}_{17} \mathrm{Nx} \mathrm{C}$-axis $\mathrm{Nd}(\mathrm{Fe}, \mathrm{TM}){ }_{12} \mathrm{~N}_{x} \mathrm{C}$-axis $\mathrm{Sm}_{2} \mathrm{Fe}_{17} \mathrm{Cx} \mathrm{C}$-axis $\mathrm{Nd}(\mathrm{Fe}, \mathrm{TM})_{12} \mathrm{C} \times \mathrm{C}$-axis

4. Magnetocrystalline anisotropy constant

$\mathrm{KSm} 2 \mathrm{Fe} 17 \mathrm{~N} 3=8 \mathrm{MJ} / \mathrm{m}^{3}$

$\mathrm{KNd}(\mathrm{Fe}, \mathrm{Mo}) 12 \mathrm{Nx}=9 \mathrm{MJ} / \mathrm{m}^{3}$

Disadvantages of $1: 12$ over $2: 17$

1. Nd-Fe Binary 1:12 compound does not exist.

2. The enhancement in $T_{c}$ is less for $1: 12$ than $2: 17$ upon nitrogenation

\section{Experimental procedure}

Elemental powders of $\mathrm{Fe}, \mathrm{Nd}, \mathrm{V}$ and Mo with more than $99.9 \%$ purity were used. Elemental powder mixtures of nominal composition were taken in a stainless steel vial (SUS 304) with balls of the same material having a diameter of $9.6 \mathrm{~mm}$. The vial containing balls and powder in the ratio of 100:1 respectively were milled at a milling speed of $95 \mathrm{rpm}$. The total weight of powder was $36 \mathrm{~g}$ and the samples were milled for 360 ks. The sealing of the vial and its opening after the completion of milling was carried out in a glove box maintained under argon atmosphere with oxygen content less than $1 \mathrm{ppm}$. The milled powders were taken in a quartz tube and a two stage heat treatment of annealing and nitriding was carried out to produce a mixture of two phase and the nitride of the hard phase respectively. The as milled, annealed and nitrided powders were characterized by X-ray diffraction. The effect of nitrogenation temperature was studied. The magnetic properties of the nitrided samples were measured in a vibrating sample magnetometer operated with a maximum field strength of $1200 \mathrm{kAm}^{-1}(15 \mathrm{kOe})$. The magnetization of the nitrogenated powder was calculated assuming the full density of $7.5 \mathrm{Mg} / \mathrm{m}^{3}$. The correction for demagnetization fields was performed using the demagnetization factor $\mathrm{N}=0.18$ obtained from the demagnetization curve of Ni powder measured by the same method.

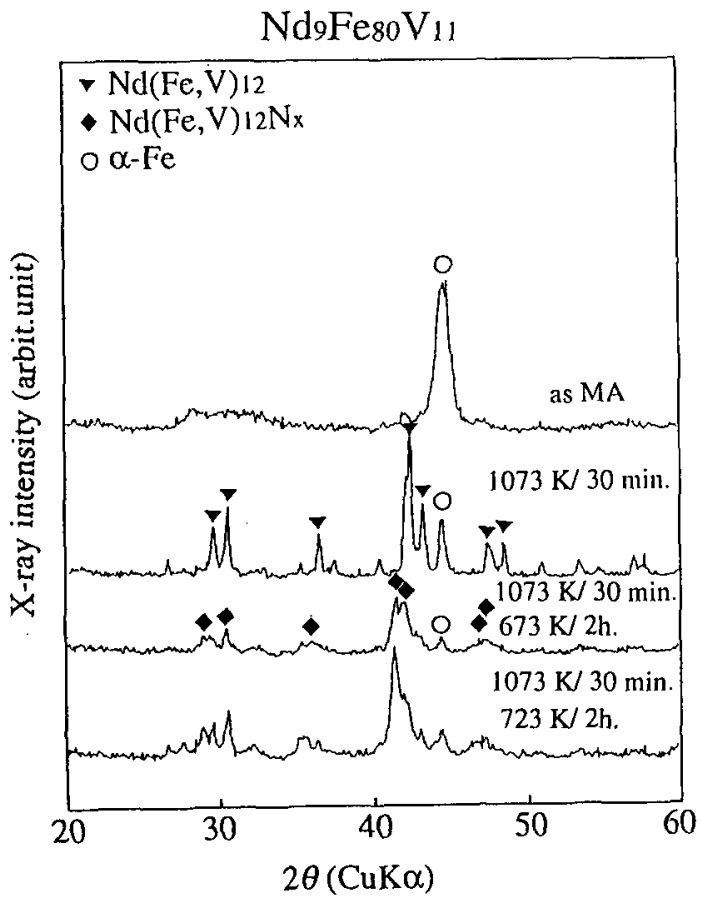

Fig.1 X-ray diffraction patterns of $\mathrm{Nd}_{9} \mathrm{Fe}_{80} \mathrm{~V}_{11}$ alloy mechanically alloyed, annealed and nitrogenated at two different temperatures. 


\section{Results and discussion}

\subsection{Nd-Fe-V system}

Fig. 1 shows the $\mathrm{X}$-ray diffraction patterns of $\mathrm{Nd}_{9} \mathrm{Fe}_{80} \mathrm{~V}_{11}$ alloy mechanically alloyed, annealed and nitrided at two different temperatures. The as milled sample shows a mixture of an amorphous phase and $\alpha-\mathrm{Fe}$. Upon annealing at $1073 \mathrm{~K}$ for $1.8 \mathrm{ks}$ a mixture of $\mathrm{Nd}(\mathrm{Fe}, \mathrm{V})_{12}$ and $\alpha$-Fe has formed. After nitrogenation the shift in the $\mathrm{Nd}(\mathrm{Fe}, \mathrm{V})_{12}$ peaks can be clearly observed. Fig. 2 shows the hysteresis loop of the alloy nitrogenated at 723 $\mathrm{K}$ for $7.2 \mathrm{ks}$. The observed remanence, coercivity and the maximum energy product are also indicated. Though the $\mathrm{X}$-ray diffraction patterns indicate a small volume fraction of $\alpha-\mathrm{Fe}$, the observed coercivity is very less. Earlier study ${ }^{20)}$ has shown that the coercivity increases significantly when nitrided under a reduced atmosphere $\left(\mathrm{N}_{2}+\mathrm{H}_{2}\right)$ than pure $\mathrm{N}_{2}$. This may help in preventing the adverse effects due to oxygen. As no oxygen analysis has been carried out during the present study, it is not possible to rationalise the causes for the observed properties. Further studies are required to improve the magnetic properties.

$\mathrm{Nd} 9 \mathrm{Fe} 80 \mathrm{~V} 11$

$1123 \mathrm{~K} / 1.8 \mathrm{ks}$ (Vac.)

$723 \mathrm{~K} / 7.2 \mathrm{ks}(\mathrm{N} 2)$

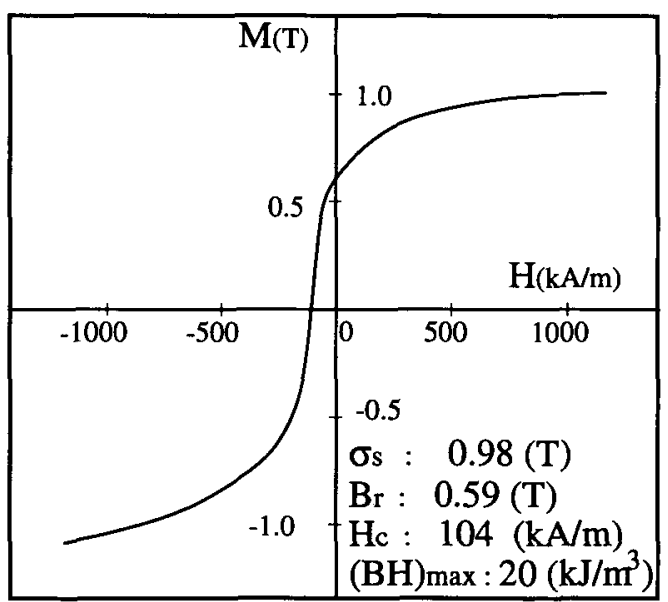

Fig.2 Hysteresis loop of $\mathrm{Nd}_{9} \mathrm{Fe}_{80} \mathrm{~V}_{11}$ alloy nitrogenated at $723 \mathrm{~K}$ for $7.2 \mathrm{ks}$. The observed magnetic properties are also indicated.

\subsection{Nd-Fe-Mo system}

A number of alloys has been tried in this system as 1:12 compound readily forms in the presence of Mo. Also, Mo is less prone to oxidation compared to V. Fig. 3 shows X-ray diffraction patterns of a number of alloys studied. It is clearly seen that the volume fraction of $1: 12$ phase is not considerable in the first two alloys, namely, $\mathrm{Nd}_{5.5} \mathrm{Fe}_{88} \mathrm{Mo}_{6.5}$ and $\mathrm{Nd}_{9} \mathrm{Fe}_{85} \mathrm{Mo}_{6}$. The volume fraction of $1: 12$ is appreciable in the other three alloy systems. Hence, the hysteresis loops of these three alloys are compared in Fig.4. In accordance with the observed X-ray diffraction patterns, $\mathrm{Nd}_{9} \mathrm{Fe}_{82} \mathrm{Mo}_{9}$ with a low volume fraction of $\mathrm{Nd}(\mathrm{Fe}, \mathrm{Mo})_{12} \mathrm{~N}_{\mathrm{x}}$ shows the smallest coercivity, whereas, the $\mathrm{Nd}_{9} \mathrm{Fe}_{80} \mathrm{Mo}_{11}$ which is nearly a single $\mathrm{Nd}(\mathrm{Fe}, \mathrm{Mo})_{12} \mathrm{~N}_{\mathrm{x}}$ phase shows the highest coercivity. $\mathrm{Nd}_{9.7} \mathrm{Fe}_{84} \mathrm{Mo}_{6.3}$ with comparable volume fraction of $\mathrm{Nd}(\mathrm{Fe}, \mathrm{Mo})_{12} \mathrm{~N}_{\mathrm{x}}$ and $\alpha-\mathrm{Fe}$ shows the optimum properties. It is interesting to note that the hysteresis loop of this alloy shows the characteristic features of a single

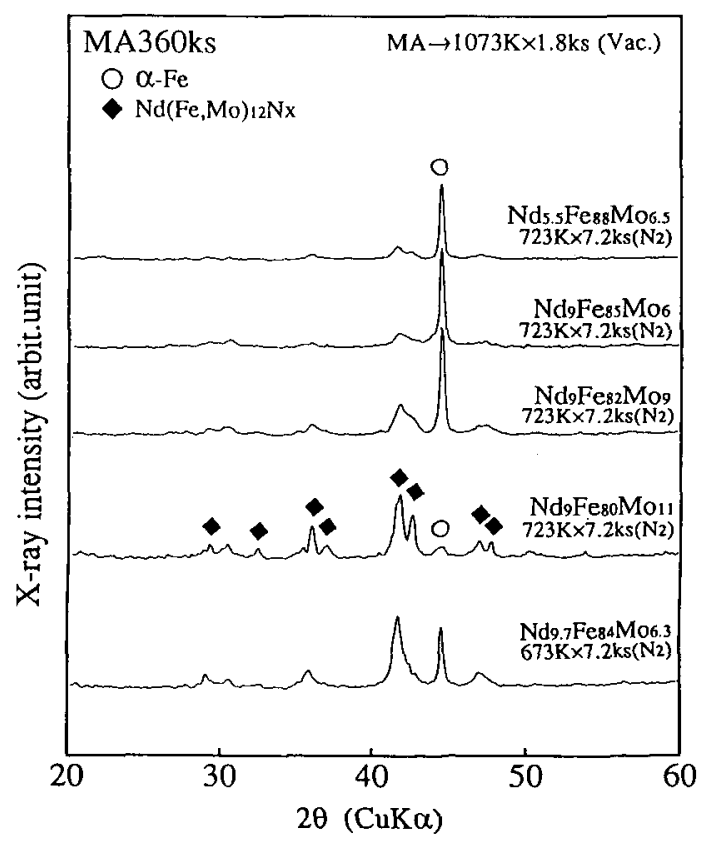

Fig.3 X-ray diffraction patterns of various Nd-Fe-Mo alloys mechanically alloyed and annealed at $1073 \mathrm{~K}$ for $1.8 \mathrm{ks}$ in vacuum. The nitrogenation conditions are as indicated. 
phase material, though indeed it contains a mixture of two phases. The maximum energy product observed in this alloy is $48 \mathrm{~kJ} / \mathrm{m}^{3}$. The alloy also exhibits a reasonable spring back as shown in Fig.4 indicating a good coupling between the hard and the soft phases. The magnetic properties of all the alloys studied are listed in Table 2.

The effect of nitrogenation condition on the magnetic properties has been studied. Fig. 5 shows the X-ray diffraction patterns of the alloys nitrided at different temperatures. It can be clearly seen that at higher nitriding temperatures the volume fraction of the hard phase, $\mathrm{Nd}(\mathrm{Fe}, \mathrm{Mo})_{12} \mathrm{~N}_{\mathrm{x}}$, decreases and the volume fraction of $\alpha-\mathrm{Fe}$ increases. The consequent effect on magnetic properties is clearly reflected in Fig.6. With increasing
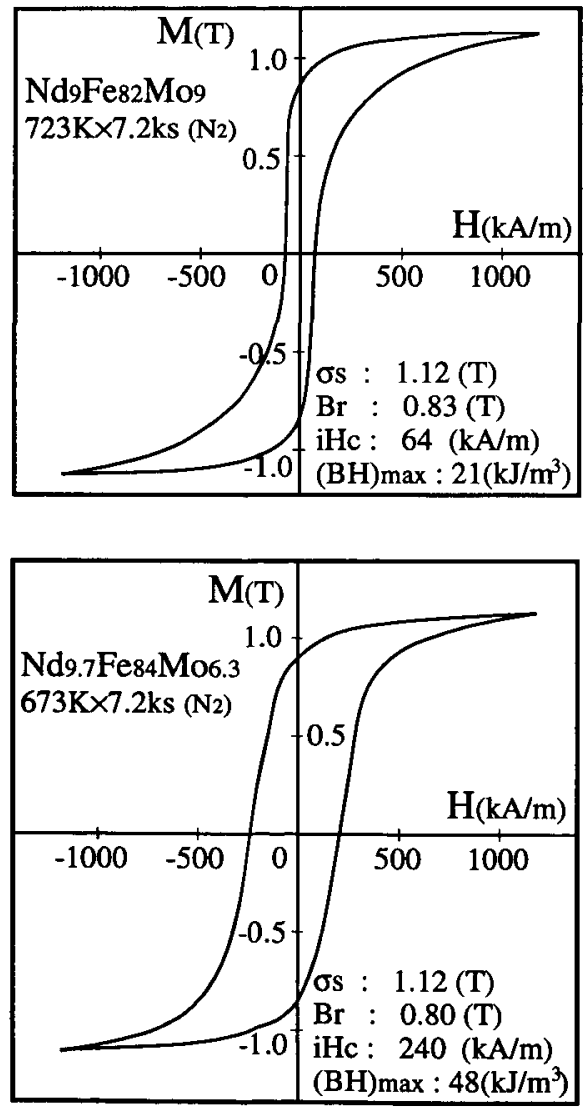

nitrogenation temperature the coercivity increases initially up to $673 \mathrm{~K}$ and decreases afterwards. At the same time remanence increases with increasing nitrogenation temperature up to $723 \mathrm{~K}$ and decreases afterwards. The maximum energy product $(\mathrm{BH})_{\max }$ as a function of nitrogenation temperature is shown in Fig.7. The highest energy is observed in the sample nitrogenated at $673 \mathrm{~K}$ for $7.2 \mathrm{ks}$. This is because up to this temperature both the coercivity and remanence increase. However, beyond $673 \mathrm{~K},(\mathrm{BH})_{\max }$ is found to decrease even though there is remanence enhancement. This is because of the large decrease in coercivity. The total variation in remanence is only $8 \%$ compared to $60 \%$ variation in coercivity. The steep fall in $(\mathrm{BH})_{\max }$ beyond $723 \mathrm{~K}$ can be attributed to the decrease in both coercivity and remanence.
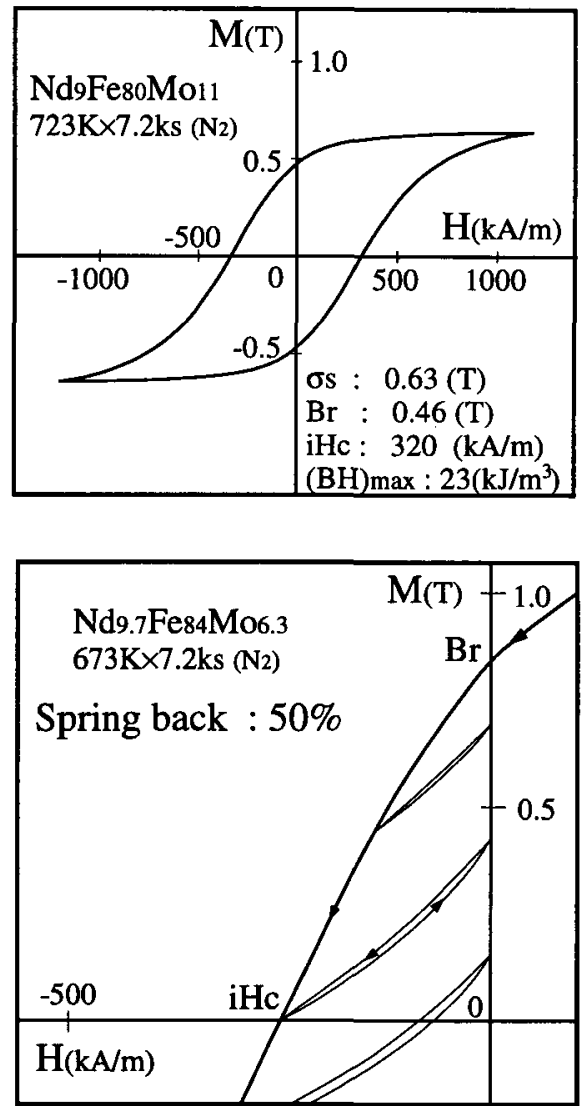

Fig. 4 Comparison between the hysteresis loops of the three different alloys of Nd-Fe-Mo. $\mathrm{Nd}_{9.7} \mathrm{Fe}_{84} \mathrm{Mo}_{6.3}$ shows good exchange spring magnetic behavior and its minor loop is also shown. 
Table 2 Summary of the observed magnetic properties of all the alloys studied.

\begin{tabular}{|l|c|c|c|c|c|c|c|c|}
\hline $\begin{array}{c}\text { Starting } \\
\text { composition }\end{array}$ & $\begin{array}{c}\text { Phase formed } \\
\text { by annealing }\end{array}$ & $\begin{array}{c}\text { Optimum } \\
\text { annealing } \\
\text { temp. (K) }\end{array}$ & $\begin{array}{c}\text { Optimum } \\
\text { nitrogenation } \\
\text { temp. (K) }\end{array}$ & $\begin{array}{c}\mathrm{Ms} \\
(\mathrm{T})\end{array}$ & $\begin{array}{c}\mathrm{Br} \\
(\mathrm{T})\end{array}$ & $\begin{array}{c}\mathrm{Hc} \\
(\mathrm{kA} / \mathrm{m})\end{array}$ & $\begin{array}{c}(\mathrm{BH}) \max \\
\left(\mathrm{kJ} / \mathrm{m}^{3}\right)\end{array}$ & $\begin{array}{c}\text { Spring } \\
\text { Back } \\
(\%)\end{array}$ \\
\hline $\mathrm{Nd} 9 \mathrm{Fe} 80 \mathrm{~V} 11$ & $\begin{array}{c}\alpha-\mathrm{Fe} \\
\mathrm{Nd}(\mathrm{Fe}, \mathrm{V})_{12}\end{array}$ & 1123 & 723 & 0.98 & 0.59 & 104 & 20 & \\
\hline $\mathrm{Nd} 9 \mathrm{Fe} 85 \mathrm{Mo6}$ & $\begin{array}{c}\alpha-\mathrm{Fe} \\
\mathrm{Nd}(\mathrm{Fe}, \mathrm{Mo})_{12}\end{array}$ & 1073 & 723 & 1.25 & 0.92 & 56 & 20 & \\
\hline $\mathrm{Nd9Fe82Mo9}$ & $\begin{array}{c}\alpha-\mathrm{Fe} \\
\mathrm{Nd}(\mathrm{Fe}, \mathrm{Mo})_{12}\end{array}$ & 1073 & 723 & 1.12 & 0.83 & 64 & 21 & \\
\hline $\mathrm{Nd9Fe80M011}$ & $\begin{array}{c}\alpha-\mathrm{Fe} \\
\mathrm{Nd}(\mathrm{Fe}, \mathrm{Mo})_{12}\end{array}$ & 1073 & 773 & 0.70 & 0.50 & 320 & 28 & \\
\hline $\mathrm{Nd} 9.7 \mathrm{Fe} 84 \mathrm{Mo6} .3$ & $\begin{array}{c}\alpha-\mathrm{Fe} \\
\mathrm{Nd}(\mathrm{Fe}, \mathrm{Mo})_{12}\end{array}$ & 1073 & 673 & 1.12 & 0.80 & 207 & 48 & 50 \\
\hline
\end{tabular}

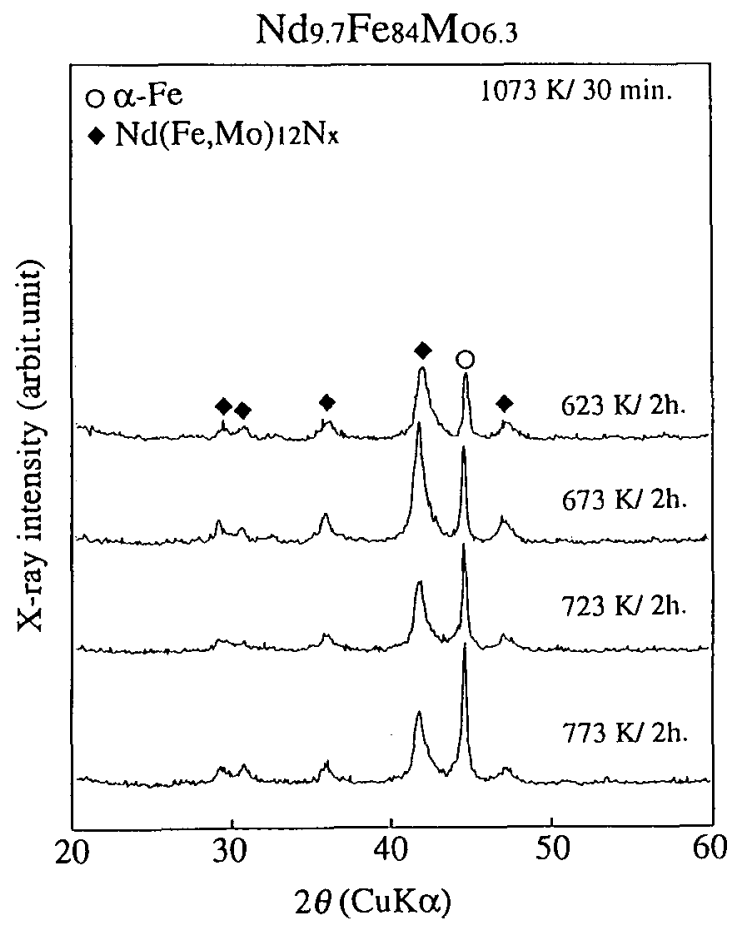

Fig.5 X-ray diffraction patterns showing the relative variation in the intensities of the $\alpha-\mathrm{Fe}$ and the $\mathrm{Nd}(\mathrm{Fe}, \mathrm{Mo})_{12} \mathrm{~N}_{x}$ peaks with the nitrogenation temperature. All the samples were annealed at $1073 \mathrm{~K}$ for $7.2 \mathrm{ks}$ in vacuum.

\section{Conclusions}

1. Mechanical alloying and a two stage heat treatment results in a mixture of hard magnetic phase $\mathrm{Nd}(\mathrm{Fe}, \mathrm{TM})_{12} \mathrm{~N}_{\mathrm{x}}$ (where $\mathrm{TM}=\mathrm{V}, \mathrm{Mo}$ ) and soft magnetic phase $\alpha$-Fe.

2. The optimum magnetic properties were observed in $\mathrm{Nd}_{9.7} \mathrm{Fe}_{84} \mathrm{Mo}_{6.3}$ alloy annealed at

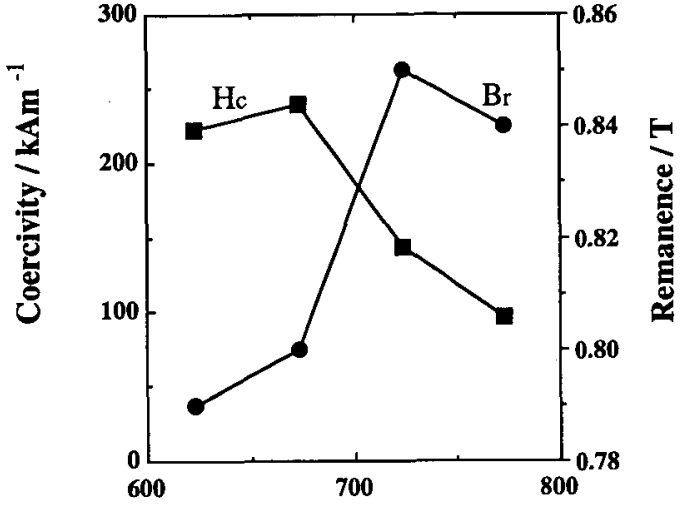

Nitrogenation temperature / $\mathbf{K}$

Fig.6 Variation in the coercivity and remanence of $\mathrm{Nd}_{9.7} \mathrm{Fe}_{84} \mathrm{Mo}_{6.3}$ samples with the nitrogenation temperature.

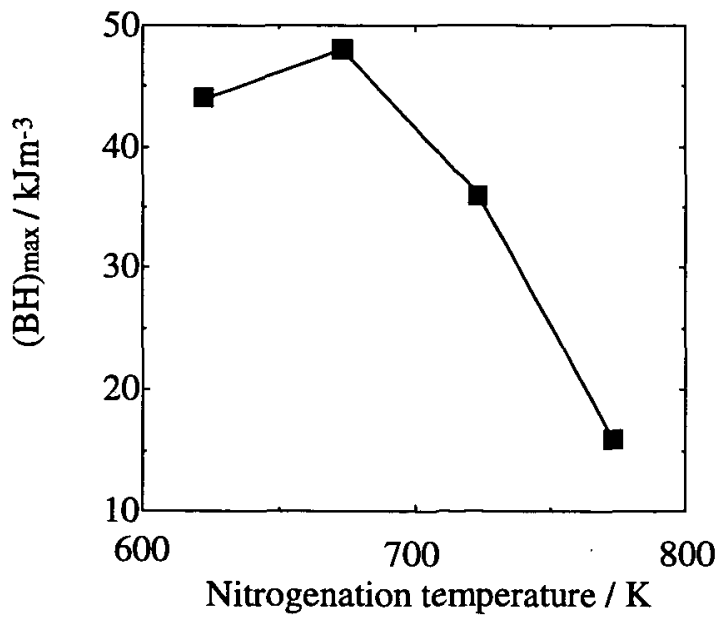

Fig.7 Variation in the maximum energy product $(\mathrm{BH})_{\max }$ of $\mathrm{Nd}_{9.7} \mathrm{Fe}_{84} \mathrm{Mo}_{6.3}$ samples with the nitrogena-tion temperature. 
$1073 \mathrm{~K}$ for $1.8 \mathrm{ks}$ and nitrided at $673 \mathrm{~K}$ for $7.2 \mathrm{ks}$ with a maximum energy product of 48 $\mathrm{kJ} / \mathrm{m}^{3}$ and a spring back of $50 \%$.

3. Nitrogenation of $\mathrm{Nd}_{9.7} \mathrm{Fe}_{84} \mathrm{Mo}_{6.3}$ at various temperature shows that beyond $673 \mathrm{~K}$ increase in the nitrogenation temperature results in the decrease of $(\mathrm{BH})_{\max }$ due to the large variation in coercivity.

\section{References}

1) L.Schultz, Mater. Forum, 88-90 (1992) 687.

2) L.Schultz, J.Wecker and E.Hellstern, $J$. Appl. Phys., 61 (1987) 3583.

3) K.Schnitzke, L.Schultz, J.Wecker and M. Katter, Appl.Phys.Lett., 57 (1990) 2853.

4) J.Wecker, M.Katter and L.Schultz, J. Appl. Phys., 69 (1991) 6058.

5) L.Schultz, K.Schnitzke, J.Wecker and M. Katter, Mat.Sci.Engr., A133 (1991) 143.

6) R.Coehoorn, D.B.de Mooij, J.P.W.B.Duchateau and K.H.J.Buschow, J.de Phys., C8 (1988) 669.

7) R.W.McCallum and A.M.Kadim, G.B. Clemente and J.E.Keem, J. Appl. Phys., 64 (1988) 5299.

8) A.Manaf, M.Leonowitz, H.A.Davis and R. A.Buckley, Proc. 12th Int. Workshop on Rare-earth Magnets and Their Applications, Canberra (1992) 1.

9) J.Ding, P.G.McCormick and R.Street, $J$. Mag. Mag. Mater., 124 (1993) 1.
10) P.G.McCormick, J.Ding, Y.Liu and R. Street, Proc. 2nd Int. Conf. on Structural Applications of Mechanical Alloying, Vancouver (1993) 349.

11) Yang Ying-Chang, Zhang Xiao-Dong, Ge Sen-Lin, Kong Lin-Shu and Pan Qi, J.Rare Earths, 9 (1991) 81.

12) K.H.J.Buschow, J. Mag. Mag. Mater., 100 (1991) 79.

13) J.M.D.Coey and Y.Otani, J. Mag. Soc. Japan, 15 (1991) 677.

14) K.H.J.Buschow and D.B.de Mooij in Concerted European Action on Magnets, eds. I.V.Mitchell, J.M.D.Coey, D.Givord, I.R. Harris and R.Hanitsch, Elsevier Applied Science, London (1989) 63.

15) J.M.D. Coey and H.Sun, J. Mag. Mag. Mater., 87 (1990) L251.

16) X.P.Zhong, R.J.Radwanski, F.R.de Boer, T.H.Jacobs and K.H.J.Buschow, J.Mag. Mag. Mater., 86 (1990) 333.

17) M.Katter, J.Wecker, L.Schultz and R. Gossinger, J.Mag.Mag.Mater., 92 (1990) L14.

18) Y.Z.Wang and G.C.Hadjipanayis, J.Appl. Phys., 70 (1991) 6009.

19) J.Ding,Y.Liu, R.Street and P.G. McCormick, J.Appl.Phys., 75 (1994) 1032.

20) T.Itsukaichi, M.Umemoto, I.Okane and H. Hirosawa, J.Jap.Soc.Powder and Powder Metallurgy, 40 (1993) 167. 